\title{
Salicylate Intoxication in an Infant: A Case Report
}

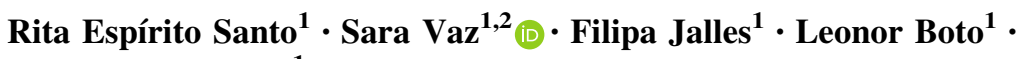 \\ Francisco Abecasis ${ }^{1}$
}

Published online: 27 November 2017

(c) The Author(s) 2017. This article is an open access publication

\begin{abstract}
In children, the most common cause of an elevated anion gap (AG) with ketonemia, ketonuria, hyperglycemia, and glycosuria is diabetic ketoacidosis. However, when the clinical history is not clear, other causes must be considered. A 9-month-old girl was transferred to our pediatric intensive care unit (PICU) because of severe metabolic acidosis. On admission, she presented with Kussmaul breathing, tachycardia, irritability, and fever. Blood gasses revealed metabolic acidosis with superimposed respiratory alkalosis and elevated AG. Fluid replacement and bicarbonate for urine alkalinization were started. Ketonemia, acidic urine with glycosuria, ketonuria, and high blood glucose prompted an insulin infusion. Measurement of plasma salicylate confirmed toxic levels. When confronted, the parents admitted to accidentally preparing the child's bottle with water containing salicylic acid $1000 \mathrm{mg}$. Although the incidence of salicylate intoxication has declined, it remains an important cause of pediatric morbidity and mortality.
\end{abstract}

Sara Vaz

sara_vaz@msn.com

1 Intensive Care Unit, Paediatric Department, Hospital of Santa Maria, Lisbon, Portugal

2 Paediatric Department, Hospital of the Holy Spirit of Ponta Delgada, São Miguel - Azores, Portugal

\section{Key Points}

As salicylate intoxication can manifest with hyperpnea, tachypnea, tachycardia, fever, coagulopathy, ketoacidosis, hyperglycemia, glycosuria, and ketonuria, it can be mistaken for other critical conditions that are more common in childhood, such as septicemia or diabetic ketoacidosis.

When an infant or child presents with increased anion gap (AG) metabolic acidosis and respiratory alkalosis, salicylate intoxication must be suspected and considered, even if caregivers deny any possibility of accidental poisoning.

Severe complications can appear when salicylate levels are decreasing or near therapeutic.

If criteria for severe intoxication (altered mental status, non-cardiogenic pulmonary edema, or nonresponsive AG acidosis) are present, extracorporeal removal of salicylate should be performed.

\section{Introduction}

Metabolic acidosis is characterized by a decrease in serum $\mathrm{pH}$ that results from either a primary decrease in plasma bicarbonate concentration or an increase in hydrogen ion concentration [1]. It is divided into processes that are associated with a normal or elevated anion gap (AG) [2]. A high AG occurs when extra-unmeasured anions are added to the blood, and early recognition is important to allow the 
clinician to formulate a differential diagnosis and understand the underlying cause [1, 3, 4].

In children, the most common causes of increased AG include diabetic ketoacidosis, lactic acidosis, poisoning (alcohol, methanol, salicylates, etc.), and kidney failure. However, infants are more likely to develop conditions that occur with normal AG metabolic acidosis [5].

Between 1950 and 1970, salicylate intoxication was the most common cause of death by poisoning in children. Safety measures were undertaken, which contributed to near eradication of aspirin-related deaths after the 1990s [6]. In spite of this decrease, salicylate intoxication remains a problem, mostly because it is not common, which causes a delay in diagnosis and, consequently, higher mortality rates [7]. Early recognition and prompt effective treatment can successfully prevent morbidity and mortality [8].

We present a case report of salicylate intoxication, its clinical manifestations, metabolic effects, and potentially life-threatening complications. Despite its now lower incidence in the pediatric emergency department (ED), it is important that physicians be alert to this condition to ensure early identification, as presentation can be misleading and therefore associated with severe consequences.

\section{Case Presentation}

A healthy 9-month-old girl with Romanian mother and Portuguese father was brought to her local hospital ED because of a history of cough, stridor, and breathing difficulty. She had experienced multiple episodes of vomiting in the preceding $24 \mathrm{~h}$ and an isolated temperature elevation of $37.5^{\circ} \mathrm{C}$ that responded to ibuprofen given by the mother. In the $\mathrm{ED}$, the infant was treated with oral dexamethasone and nebulized adrenaline without improvement in symptoms. Laboratory evaluation was normal, and venous blood gases showed $\mathrm{pH}$ 7.36, $\mathrm{pCO}_{2} 18.4 \mathrm{mmHg}$, bicarbonate $11.1 \mathrm{mmol} / 1$, chlorine $125 \mathrm{mmol} / \mathrm{l}$. Severe metabolic acidosis prompted transfer to our pediatric intensive care unit (PICU).

On PICU admission, the girl had Kussmaul breathing, tachycardia $(205 \mathrm{pm})$, irritability, and fever $\left(38.5^{\circ} \mathrm{C}\right)$. The parents denied any possibility of accidental or intentional toxic ingestion. We proceeded to provide fluids and bicarbonate replacement.

Blood gases measured in the PICU were $\mathrm{pH} 7.37, \mathrm{pCO}_{2}$ $13.6 \mathrm{mmHg}$, bicarbonate $11.1 \mathrm{mmol} / \mathrm{l}$, chlorine $129 \mathrm{mmol} /$ 1, base excess (BE) - $17.5 \mathrm{mmol} / \mathrm{l}, \mathrm{AG} 27 \mathrm{mmol} / \mathrm{l}$, and lactate $36 \mathrm{mg} / \mathrm{dl}$. Given the elevated lactate levels, along with the persistent hyperthermia $\left(39^{\circ} \mathrm{C}\right)$, lack of response to antipyretics, and sinus tachycardia $(210 \mathrm{bpm})$, a fluid bolus was given and antibiotic therapy (ceftriaxone) started. Laboratory results showed no signs of infection.
Urinalysis revealed acidic urine $(\mathrm{pH} 5)$, glycosuria (67 mg/dl; normal range $<15)$, and ketonuria $(150 \mathrm{mg} / \mathrm{dl})$. At first, capillary glycemia was normal $(106 \mathrm{mg} / \mathrm{dl})$, but she had ketonemia $(4.5 \mathrm{mg} / \mathrm{dl})$. After some hours, glycemia increased to $225 \mathrm{mg} / \mathrm{dl}$, and therapy with fluid infusion plus intravenous insulin was started.

\section{Investigations}

Despite these therapeutic measures, compensated metabolic acidosis with low bicarbonate, elevated AG, and decreased BE persisted. The possibility of ingestion of an anion-forming substance was considered, and plasma salicylate levels revealed toxic values $(76 \mathrm{mg} / \mathrm{dl}$; normal range $<20 \mathrm{mg} / \mathrm{dl}$ ). The parents were confronted and finally admitted to accidentally preparing the child's formula with water containing Aspegic $1000 \mathrm{mg}^{\circledR}$ (DL-lysine acetylsalicylate $1000 \mathrm{mg}$ ).

\section{Differential Diagnosis}

The differential diagnosis was sepsis, diabetic ketoacidosis, and other toxicities.

\section{Treatment}

After $23 \mathrm{~h}$, salicylates decreased to $39.1 \mathrm{mg} / \mathrm{dl}$, but the patient's clinical condition was worsening. She became oligo-anuric, with bilateral crackles on auscultation and low peripheral oxygen saturation. She had a self-limiting seizure, requiring no therapeutic intervention.

Treatment with continuous venovenous hemodiafiltration (CVVHDF) was started. Salicylate levels decreased to $10.3 \mathrm{mg} / \mathrm{dl}$ after $7 \mathrm{~h}$ of CVVHDF.

Therapy with bicarbonate replacement was maintained until $48 \mathrm{~h}$ of hospitalization, when urine $\mathrm{pH}$ was 9 and plasma salicylate level was $0.7 \mathrm{mg} / \mathrm{dl}$.

Although the blood was negative for salicylates, unstable glycemia and ketonemia values persisted. Blood glucose levels oscillated between 36 and $460 \mathrm{mg} / \mathrm{dl}$ and blood ketone bodies between 0.6 and $4.9 \mathrm{mg} / \mathrm{dl}$ (Fig. 1). Insulin and fluid therapy were maintained for $72 \mathrm{~h}$.

\section{Outcomes and Follow-Up}

On day 4 of the PICU stay, clinical improvement was noted, with apyrexia, normal glycemia, and negative ketonemia. She was transferred back to the referring 
Fig. 1 Evolution over time of salicylate levels (a), glycemia (b), and ketonemia (c)
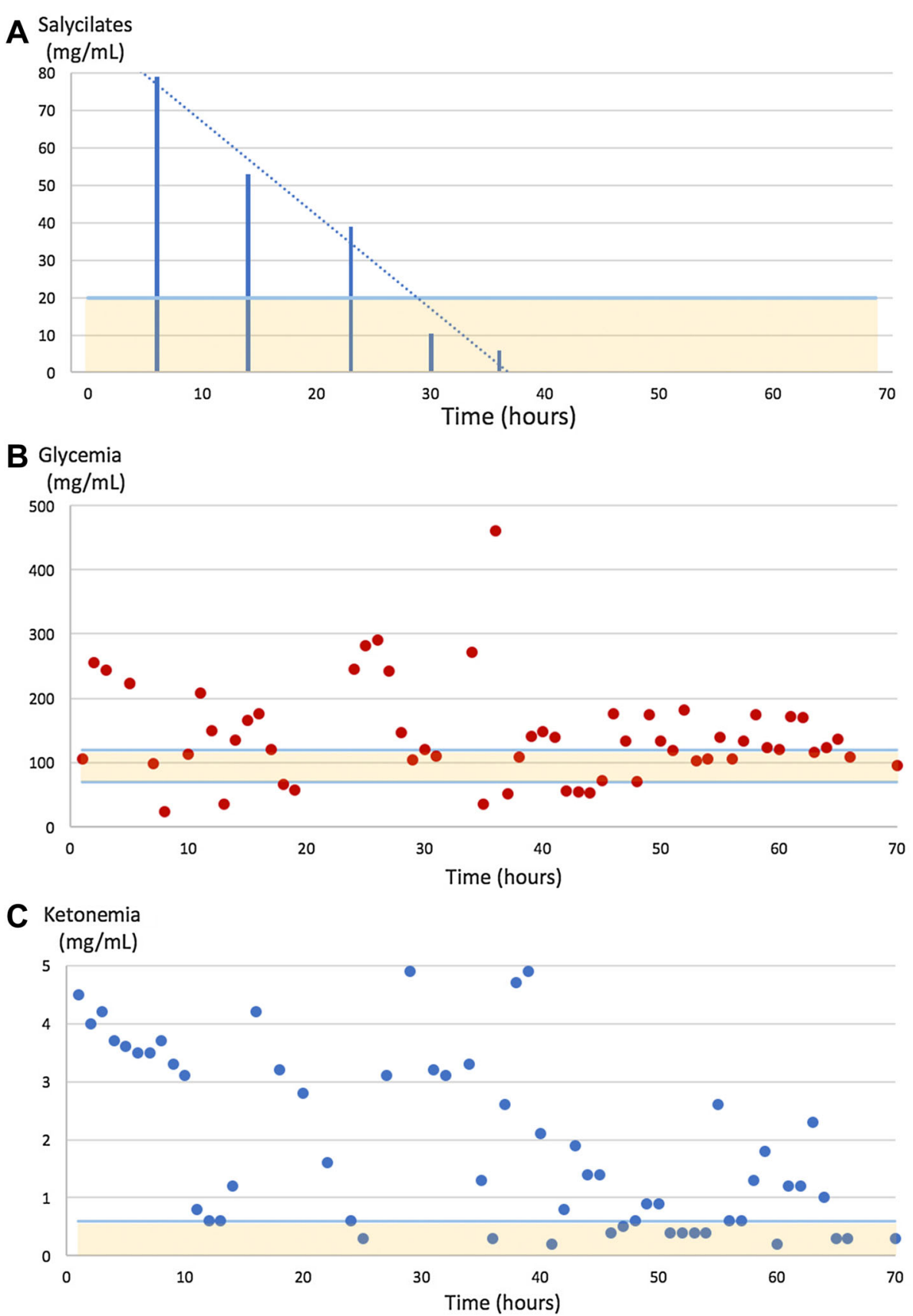

hospital where the local social services were contacted; she was discharged after $48 \mathrm{~h}$ of medical surveillance.

\section{Discussion}

Salicylates are pharmacological agents that can cause fatal poisoning in children. They are weak acids that, when uncharged in a metabolic acidosis environment, can move easily across cellular barriers, including the blood-brain barrier, and are responsible for tissue toxicity [9]. Manifestations are nonspecific and diverse, demanding a high index of suspicion to avoid delayed diagnosis and treatment [10]. Salicylates stimulate the medullary respiratory center of the medulla, causing tachypnea and hyperventilation and therefore respiratory alkalosis. Consequently, they can cause nausea and vomiting via direct stimulation of the chemoreceptor trigger zone in the medulla. Respiratory alkalosis secondary to hyperventilation is critical to survival as it prevents central nervous system toxicity. On the other hand, it plays a role in the development of metabolic acidosis via uncoupling of oxidative phosphorylation in the mitochondria, which leads to accumulation of organic acids, including lactic acid and keto acids [10]. 
The hallmarks of acute salicylate overdose are hyperventilation leading to respiratory alkalosis, hyperthermia, and increased AG metabolic acidosis, which were all present in this clinical case.

Salicylate intoxication can be very misleading, especially when there is occult exposure, as in this case. The initial findings of tachypnea, high fever, high lactate levels, and metabolic acidosis mimicked sepsis [11]. The negative infection parameters in laboratory evaluations made this diagnosis less likely. As such, diabetic ketoacidosis was suspected, as it can have the same clinical presentation: hyperglycemia, AG metabolic acidosis, ketonuria, and ketonemia [12]. The degree of acidosis is less pronounced in salicylate intoxication because of simultaneous respiratory alkalosis. Salicylate intoxication induces complex alterations in carbohydrate metabolism, leading to hyperglycemia or hypoglycemia, particularly in infants. Hyperglycemia can result from glycogenolysis, stimulation of gluconeogenesis, and decreased peripheral utilization of glucose [12]. The alterations in glucose homeostasis can persist even when salicylate levels are undetectable, as in this case.

The Extracorporeal Treatments in Poisoning (EXTRIP) workgroup recommends bicarbonate as the first-line therapy [13]. Bicarbonate produces alkalemia and alkaluria. Alkalemia minimizes the passage of salicylates to the central nervous system, whereas alkaluria promotes renal excretion of salicylate [14]. It also involves correction of fluid and electrolyte imbalance. Urinalysis to monitor urine $\mathrm{pH}$ is important, as it is a good predictor of alkalinization success [15].

The EXTRIP workgroup recommendations for initiating extracorporeal treatment are salicylate levels $>100 \mathrm{mg} / \mathrm{dl}$, salicylate levels $>90 \mathrm{mg} / \mathrm{dl}$ with impaired renal function, altered mental status, or new hypoxemia requiring supplemental oxygen [13].

Our patient's salicylate levels were below the reference level required to start extracorporeal treatment $(76 \mathrm{mg} / \mathrm{dl})$. However, in spite of decreasing salicylate levels, she was clinically deteriorating and progressed to severe salicylate intoxication (characterized by the presence of altered mental status and acute respiratory distress syndrome requiring supplemental oxygen). The development of any of these situations is an indication for extracorporeal removal of salicylates, which can be achieved with hemodialysis, CVVHDF, peritoneal dialysis, hemoperfusion, and transfusion exchange in newborns [14]. Extracorporeal treatment offers advantages over bicarbonate administration, including more rapid clearance of salicylates and a more predictable correction of acidosis [13]. After $7 \mathrm{~h}$ of treatment, the infant showed clinical improvement without further signs or symptoms.
Life-threatening complications of salicylate intoxication may occur when plasma concentrations are decreasing or near therapeutic, as happened in this case, where clinical deterioration occurred after $23 \mathrm{~h}$ of treatment [15]. Therefore, frequent plasma salicylate monitoring is not recommended, and clinical decisions should not be made solely based on this level [13].

\section{Conclusion}

Salicylate poisoning is a severe pediatric emergency and should be considered in children who present with unexplained metabolic acidosis and respiratory alkalosis. Prognosis in this disorder depends on early recognition and management.

Acknowledgements The authors gratefully acknowledge Marisa Vieira, MD and Joana Rios, MD for the support and clinical care.

\section{Compliance with Ethical Standards}

Funding No financial support was received for the preparation of this report.

Conflict of interest Rita Espírito Santo, Sara Vaz, Filipa Jalles, Leonor Boto and Francisco Abecasis have no conflicts of interest that are directly relevant to the content of this report.

Consent Written informed consent was obtained from the parents of the patient for publication of this case report. A copy of the written consent may be requested for review from the corresponding author.

Open Access This article is distributed under the terms of the Creative Commons Attribution-NonCommercial 4.0 International License (http://creativecommons.org/licenses/by-nc/4.0/), which permits any noncommercial use, distribution, and reproduction in any medium, provided you give appropriate credit to the original author(s) and the source, provide a link to the Creative Commons license, and indicate if changes were made.

\section{References}

1. Kraut JA, Madias NE. Metabolic acidosis: pathophysiology, diagnosis and management. Nat Rev Nephrol. 2010;6(5):274-85.

2. Reddy P, Mooradian AD. Clinical utility of anion gap in deciphering acid-base disorders. Int J Clin Pract. 2009;63:1516-25.

3. Kraut JA, Madiast NE. Serum anion gap: its uses and limitations in clinical medicine. Clin J Am Soc Nephrol. 2007;2(1):162-74.

4. Ingelfinger JR, Kraut JA, Madias NE. Lactic acidosis. N Engl J Med. 2014;371(24):2309-19.

5. Kliegman RM. Nelson textbook of pediatrics. Philadelphia: Elsevier; 2016.

6. Chyka PA, Erdman AR, Christianson G, Wax PM, Booze LL, Manoguerra AS, et al. Salicylate poisoning: an evidence-based consensus guideline for out-of-hospital management. Clin Toxicol (Phila). 2007;45(2):95-131.

7. Thisted B, Krantz T, Strm J, Srensen MB. Acute salicylate self poisoning in 177 consecutive patients treated in ICU. Acta Anaesthesiol Scand. 1987;31(4):312-6. 
8. Dargan PI, Wallace CI, Jones AL. An evidence based flowchart to guide the management of acute salicylate. Emerg Med J. 2002;19(3):206-9.

9. Chyka PA, Erdman AR, Christianson G, Wax PM, Boole LL, Manoguerra AS, et al. Salicylate poisoning: an evidence-based consensus guideline for out-of-hospital management. Clin Toxicol (Phila). 2007;45:95-131.

10. Ayalon I, Alder M, Langner T, Hafberg E, Miethke A, Kaplan J. A case of salicylate intoxication complicated by coagulopathy, pulmonary edema, and pancreatitis. Am $J$ Ther. 2016;23(6):1929-32.

11. Haslinger V, Dietz W, Bartsch M, Simma B. Salicylate intoxication with symptoms of septicaemia in a 17-month-old girl. Klin Padiatr. 2011;223:436-7.
12. Bideci A, Yeşilkaya E. Salicylate intoxication masquerading as diabetic ketoacidosis in a child. Pediatr Int. 2008;50(4):605.

13. Juurlink DN, Gosselin S, Kielstein JT, Ghannoum M, et al. Extracorporeal treatment for salicylate poisoning: systematic review and recommendations from the EXTRIP Workgroup. Ann Emerg Med. 2015;66(2):165-81.

14. Papacostas M, Hoge M, Baum M, Davila S. Use of continuous renal replacement therapy in salicylate toxicity: a case report and review of the literature. Heart Lung. 2016;45(5):460-3.

15. Rivera W, Kleinschmidt K, Velez L, Shepherd G, Keyes DC. Delayed salicylate toxicity at 35 hours without early manifestations following a single salicylate ingestion. Ann Pharmacother. 2004;38(7):1186-8. 